\title{
Injil Barnabas dan Makna Pentingnya dalam Studi Heresiologi
}

\author{
Yosef Yunandow Siahaan ${ }^{1)}$ \\ 1) Sekolah Tinggi Teologi Injili Indonesia Surabaya-Mojokerto \\ E-mail:yosefsiahaan@sttii-surabaya.ac.id
}

\begin{abstract}
The Portrait of Jesus in the Apocryphal Gospels often contradicts the Portrait of Jesus in the Canonical Gospels in the New Testament. For evangelical-orthodox Christianity, the canon of the Scriptures has been final, and has been endorsed at the Hippo and Carthage councils, however some Muslims always make the news that the Apocryphal Gospels, especially the Gospel of Barnabas, are the original Gospels, while the gospels accepted by Christians today is a false gospel. This interest is worth examining aside, looking into the texts of the Gospel of Barnabas insofar as they pertain to Biblical Teaching. This study will use a biblical approach to library research. Namely by looking at the texts in the Gospel of Barnabas and comparing them with the Bible text of the New Testament by doing a little exposition of some parts of the Bible. After all, the Bible is the primary source because it comes from direct eye witnesses and is only fifteen to sixty years apart from the time Jesus lived. The problem is that the Gospel of Barnabas has been mentioned in the Pseudo Gelasius I Decree which seems to support that the Gospel of Barnabas was written by the Apostle Barnabas during his lifetime. However, it is easy to trace that the Gospel of Barnabas contains many trivial errors that could not have been written by the Apostle Barnabas who had a Jewish background, living in the Palestinian-Israel area in the first century AD. Doing a study of the time of writing, writers, geographic and religious background, and language, if necessary the theological motive needs to be done in order to study the study of Heresiology or teachings that deviate from the truth of Evangelical-Orthodox Christianity.
\end{abstract}

Keywords: Gospel of Barnabas, Heresiology, Heresiography, Canonical Book

\begin{abstract}
Abstrak
Potret Yesus dalam Injil-Injil Apokrif seringkali bertolak belakang dengan Potret Yesus dalam Injil-Injl Kanonik yang ada dalam Alkitab Perjanjian Baru. Bagi kekristenan yang Injili-ortodoks kanon Kitab suci telah bersifat final, dan telah disahkan pada konsili Hippo dan Kartago, Namun sebagian umat Islam selalu membuat berita bahwa Injil-injil Apokrif khususnya Injil Barnabas adalah Injil yang asli, sedangkan injil yang diterima orang Kristen saat ini adalah Injil yang palsu. Minat tersebut layak dikaji di samping, melihat ke dalam teks-teks Injil Barnabas sejauh itu bersinggungan dengan Ajaran Alkitab. Penelitian ini akan menggunakan pendekatan penelitian kepustakaan yang bersifat biblika. Yaitu dengan melihat teks-teks dalam Injil Barnabas dan membandingkan dengan teks Alkitab Perjanjian Baru dengan melakukan sedikit eksposisi dari beberapa bagian Alkitab. Bagaimanapun juga Alkitab adalah sumber primer karena berasal dari saksi mata langsung dan hanya berjarak lima belas hingga enam puluh tahun sejak Yesus hidup. Masalahnya Injil Barnabas pernah di sebut dalam Dekrit Pseudo
\end{abstract}


Gelasius I yang tampaknya mendukung bahwa Injil Barnabas di tulis oleh Rasul Barnabas semasa hidupnya. Namun mudah saja di lacak bahwa Injil Barnabas mengandung banyak kesalahan-kesalahan sepele yang tidak mungkin di tulis oleh Rasul Barnabas yang berlatar belakang Yahudi, tinggal di daerah Palestina-Israel pada abad pertama Masehi. Melakukan kajian terhadap waktu penulisan, penulis, latar belakang geografi dan keagamaan, dan Bahasa, jika diperlukan motif teologisnya perlu dilakukan dalam rangka mempelajari studi Heresiologi atau ajaran-ajaran menyimpang dari kebenaran InjiliOrtodoks kekristenan.

Kata Kunci: Injil Barnabas, Heresiologi, Heresiografi, Kitab Kanonik

\section{PENDAHULUAN (INTRODUCTION)}

Sesudah kepengarangan keempat Injil, memang beredar Injil-Injil Apokrif yang paling awal di tulis tahun $150 \mathrm{M}$, seperti Injil Protoevangelium of James, Injil Thomas, Injil petrus dll. ${ }^{1}$ Dengan dimunculkannya Injil-injil Apokrif dan khususnya Injil Barnabas adalah Injil yang asli maka, berarti pihak Kristen tidak diberi ruang dan tempat untuk berhak menentukan sendiri imannya dalam dialog kedua agama yaitu Kristen dan Islam. Padahal syarat dialog yang berarti adalah jika kedua belah pihak berhak menentukan sendiri apa yang diyakininya. ${ }^{2}$ Untuk melakukan tinjauan kritis diperlukan melihat beberapa dokumen heresiograf (tulisan-tulisan palsu), dan membandingkannya dengan dokumen kanonik dan dokumen sejaman agar dapat menganalisa dari banyak sisi tentang Injil

\footnotetext{
${ }^{1}$ Jk. Elliott, The Apocryphal New Testament, Oxford: Oxford University Press, 2005.

2 T. H. van Den End, Sejarah Perjumpaan Gereja dengan Islam, Jakarta: Sekolah Tinggi Teologia, 1978
}

barnabas ini

Dalam edisi Bahasa Arabnya bahkan Injil Barnabas harus dilihat sebagai kelanjutan pencarian Islam akan bukti ajaran Islam dari kesaksian Alkitab. Sepanjang sejarah, telah

menjadi fenomena umum bahwa umat Islam berpendapat bahwa kerasulan Muhammad telah dinubuatkan di dalam Alkitab. $^{3}$

Injil Barnabas sudah pasti tidak ditulis oleh seorang yang mengenal Yesus atau salah seorang Rasul. Injil Barnabas pasti tidak berasal dari abad-abad pertama sesudah Masehi. Dari Gereja Purba, yakni abad-abad pertama sesudah Masehi, kita sama sekali tidak memiliki satu manuskrip pun dari Injil Barnabas, dan tidak ada bukti bahwa naskah Barnabas pernah dikenal oleh Gereja Purba. Karena kurun jaman antara Injil Barnabas dengan abad pertama sesudah Masehi sedemikian jauhnya, tidak

\footnotetext{
${ }^{3}$ Umar Ryad, IN PURSUIT OF A 'TRUE' GOSPEL: RIḍA'S ARABIC EDITION OF THE GOSPEL OF BARNABAS, JSTOR: BRILL
} 
Jurnal Teologi \& Pelayanan ( Kerusso )

E-ISSN: 2714-9587

P-ISSN: 2407-554X

ada satu alasan pun untuk menempatkan

disebut Decretum

Pseudo

Injil Barnabas sederajat bahkan melebihi Injil-Injil Kanonik. ${ }^{4}$

Tentu, Penggunaan Injil-injil

Gelasianum $($ Decretum $=$ surat keputusan Paus; pseudo $=$ yang tidak asli). Dalam surat keputusan Paus itu dicantumkan Kanonik dan Kitab-Kitab dalam Perjanjian Baru sebagai sumber primer (Primary Resource) kehidupan Yesus bukan hanya karena Kitab ini diterima oleh Gereja mula-mula, tetapi Injil-Injil Kanonik adalah sumber literature yang hanya berjarak belasan hingga puluhan tahun dari masa di mana Yesus hidup. Penggunaan pendekatan sejarah sekuler untuk merekonstruksi kehidupan tokoh historis pastilah harus melacak sumber primernya dimana semua saksi mata masih hidup. ${ }^{5}$

Masalahnya dalam Dekrit PseudoGelasius, seolah-olah menampakkan bahwa buku ini sudah ada sejak zaman Paus Gelasius. Menyamakan Injil Barnabas dengan apa yang tertulis dalam Dekrit sama dengan ingin membangun sebuah argument bahwa Injil ini di tulis oleh Murid dari Rasul Barnabas dan masih dekat dengan masa Yesus. Begitulah dalam Gereja Purba pernah disebut adanya sebuah "injil Barnabas".

"Injil" itu untuk pertama kalinya dicantumkan dalam apa yang

\footnotetext{
${ }^{4}$ Jan Slomp. Pseudo Barnabas in the context of Muslim-Christian Apologetics, dalam Al-Mushir XVl (1474). hlm. 123-126

${ }^{5}$ Bambang Noorsena, Telaah Kritis terhadap Injil Barnabas (Asal-Usul, Historisitas dan Isinya), Yogyakarta: Andi Offset, 1990 hal 3
} diakui sebagai kanonik (= berwibawa); dalam daftar itu disebut juga "'injil" Barnabas. Daftar itu berasal dari abad keenam sesudah Masehi. Berita yang lebih tua tentang "injil" itu tidak ada! ${ }^{6}$

Penelitian ini akan membahas mengenai tinjauan kritis terhadap Injil Barnabas dengan menyajikan pengarang injil ini, waktu penulisannya, ajaran-ajaran yang ada di dalamnya, Pro dan Kontra terhadap injil tersebut. Baru kemudian menyajikan bukti-bukti internal dan eksternal dari Injil Barnabas. Serta beberapa eksposisi teks-teks Alkitab untuk meninjau hal itu.

Diharapkan melalui penelitian ini, dalam dialog kedua agama timbul sikap kesalingpahaman, dan Kekristenan mampu meluruskan dalam rangka mempergunakan hak jawabnya ketika imannya disalahpahami. Dan mengambil sikap terhadap Injil-injil Apokrif semacam Injil

\footnotetext{
${ }^{6}$ Decretum Gelasianum periksa E. Hennecke-W. Schneemelcher, New Testament Apocrypha, London, 1973, hlm. 46-49 juga E. Schwartz, Zeitschrift fur Neuestestamentliche Wissensehaft, 29 (1930), hlm. 161-168. Dekrit itu untuk sebagian berasal dari jaman Paus Gelasius (492-496), akan tetapi berbagai-bagai bagian, a.1. justru daftar dengan buku-buku yang ditolak, berasal dari permulaan abad ke-6.
} 
Barnabas terkait asal-susulnya, isi dan historisitasnya.

\section{METODE PENELITIAN (RESEARCH METHOD)}

Metode yang digunakan dalam pemecahan permasalahan penelitian ini menggunakan pendekatan studi pustaka, secara khusus menggunakan sudut pandang biblika. Peneliti akan membandingkan teks dalam Injil Barnabas dengan Teks Alkitab yang merupakan sumber primer mengenai Yesus dan kekristenan. Penelitian ini tidak serta merta menyajikan data dengan berat sebelah, namun akan berusaha menampilkan dari Pihak yang Pro dan Kontra baru setelah itu di lakukan analisis kritis terhadap keduanya.Setelah itu, peneliti akan mengkaji Injil Barnabas berdasarkan pengamatan terhadap historisitas kanon Alkitab.

\section{HASIL DAN PEMBAHASAN}

(RESULTS AND DISCUSSION )

\section{Penyebutan Injil Barnabas dalam Dekrit}

Pseudo-Gelasius I (Decretum Pseudo Gelasianum)

Diantara 60 Kitab yang terdaftar dalam Dekrit Pseudo-Gelasius I memang terdapat Injil Barnabas sebagai satu diantara 60 Kitab yang di larang dibaca oleh Paus Gelasius I yang menjabat dari tahun 492496 M. Ada kemungkinan sebagai orang
Yahudi yang menjadi korban inkuisisi Gereja Katolik Roma dan dipaksa hidup sebagai orang Kristen, Kemudian dia berkenalan dengan agama Islam dan agaknya merasa tertarik kepada agama ini. Lalu dikarangnya Barnabas untuk menunjukkan kepada orang akan arti Muhammad. $^{7}$

\section{Historisitas Injil Barnabas}

Naskah Injil Barnabas yang dipublikasikan dan menjadi dikenal sejak di publikasikan oleh Clarendom Press, Oxford, hasil alih Bahasa yang dilakukan oleh Lonsdale Ragg dan Laura Ragg ke dalam Bahasa Inggris. Bahasa Asli injil ini yaitu Bahasa Italia. Yang diperkirakan berasal dari abad ke-16. ${ }^{8}$ Injil ini dianggap oleh sebagian besar akademisi, termasuk dari kalangan Kristen dan sebagian Muslim (seperti Abbas el-Akkad) datang terlambat dan pseudopigrafa; $;{ }^{9}$

Injil ini dalam terjemahaannya Mengidentifikasi dirinya sebagai terjemahan Italia dari Injil abad pertama, sekarang berada di Museum Wina. Pada 1970-an, salinan terjemahan bahasa Spanyol abad kedelapan belas muncul

\footnotetext{
${ }^{7}$ Jan Slomp. Pseudo Barnabas in the context of Muslim-Christian Apologetics, dalam Al-Mushir XVl (1474). hlm. 123-126.

${ }^{8}$ A M I N A I N L O E S, The Gospel of Barnabas: A Muslim

Forgery?, Source of Islamic Knowledge, 49

${ }^{9}$ Joosten, Jan. "The Gospel of Barnabas and the Diatessaron". Harvard Theological Review. 95 (1): 73-96, 2002
} 
kembali dalam koleksi pribadi di Australia. $^{10}$ Meskipun tidak lengkap, salinan bahasa Spanyol memberikan petunjuk yang tidak dimiliki bahasa Italia: kata pengantar yang menceritakan bagaimana seorang Fra Marino mencuri Injil kuno dari perpustakaan Vatikan ketika Paus sedang tidur siang, kemudian dia menjadi seorang Muslim, mengubah namanya menjadi Mustafa de Aranda, dan menerjemahkannya untuk menyebarkan pesan. $^{11}$

Barnabas membangkitkan minat yang cukup besar di antara abad: orang terpelajar di Inggris, yang kepadanya dua salinan berbeda dari dokumen itu diketahui dan, sampai batas tertentu, dapat diakses. Salah satu teks bahasa Spanyol ini adalah teks Italia, yang sekarang kami terbitkan atau pertama kali di halaman-halaman berikutnya; yang lainnya,Spanyol versi, yang mengaku diterjemahkan dari bahasa Italia, yang sayangnya telah menghilang dari pandangan. ${ }^{12}$

\section{Isi Injil Barnabas}

\footnotetext{
${ }^{10}$ Jan Joosten, 'The Gospel of Barnabas and the Diatessaron', in Harvard Theological Review XCV (2002), 73-96

${ }^{11}$ F. P. Cotterell, 'The Gospel of Barnabas', in Vox Evangelica X (1977), 43-47; J. E. Fletcher, 'The Spanish Gospel of Barnabas', in Novum Testamentum XVIII, Fasc. 4 (1976), 314-320

12 Lonsdale dan Laura Ragg, The Gospel Of Barnabas, Edited and translated form Italian Ms, Oxford, Clarendon Press.
}

\section{Isi terkait Keagamaan}

Pada Judul "Injil" ini, terdapat beberapa kalimat yang ditulis oleh penulisnya yaitu:

Injil yang benar tentang Yesus yang bergelar Kristus, seorang Nabi baru yang diutus Allah ke dunia: Menurut uraian Barnabas RasulNya.

True Gospel of Jesus, Called Christ, A New Prophet Sent By God to the World: According to the Description Of Barnabas, His Apostle

Yang berasal dari Bahasa Italianya:

Vero euangelio di essu chiamato chrissto nouo profeta mandate da DIG al modo secondo la descritione di arnaba appostolo suo $^{13}$

Di bawah judul di atas di sebutkan,

Barnabas, Rasul Yesus orang Nazaret yang bergelar Kristus (Barnabas, apostle of Jesus the Nazarene, Called Christ).

Namun di Pasal 96 Injil Tersebut Yesus justru mengaku Ia bukan Mesias. Gaya sumpah Yesus yang sama sekali tidak pernah dijumpai dalam Injil Kanonik

Jesus answered : As God liveth b, in whose presence my soul standeth, I am not the Messiah whom all the tribes of the earth expect, even as God promised to our father Abraham

Yang dapat diterjemahkan

"Demi Allah, pada diri-Nya, Jiwaku berdiri, bahwa Aku bukanlah Messias itu........." 
Dan hamper di setiap pasal gaya sumpah Yesus selalu menggunakan," As God liveth...."

Selain itu pada pasal 152 Injil tersebut menceritakan di waktu hari Sabat, Yesus memasuki Bait Suci di Yerusalem dan Tentara Militer Romawi datang dan memasuki Bait Suci itu untuk mengganggu Dia.

Jesus having come to Jerusalem, and having entered one Sabbath day into the Temple, the soldiers drew nigh to tempt him and take him, and they said : Master, is it lawful to wage war

Keempat, Terkait penetapan tahun Yobel dalam Injil ini yang tidak sesuai dengan yang tertulis dalam Taurat yaitu serratus tahun,

Sesudah sembahyang malam murid-murid mendekat kepada Yesus, kemudian Yesus bersabda: "Malam ini tepat waktunya bagi Messias, pesuruh Allah itu, akan menjadikan tahun Yobel tiap-tiap tahun, yang sekarang itu jatuh pada setiap 100 tahun (This night shall be in the time of Messiah, Messenger of God, The Jubilee every Year that now cometh hundredyear")

\section{Terkait Letak Geografis}

Pasal 20 Injil Barnabas menjelaskan bahwa Yesus pergi ke Galilea dengan sebuah perahu dan berlayar ke Kota Nazareth:

Jesus went to the sea of Galilee, and having embarked in a ship sailed to his city of Nazareth
(Yesus pergi ke Laut Galilea, dan turun ke dalam perahu untuk berlayar ke kotanya, Nazaret).

Sedangkan di Pasal 21, Injil ini menyebutkan:

Mendakilah Yesus ke Kapernaum (Jesus went up to Capernaum, and as he drew near to the city behold there came out of the tombs)

\section{Terkait Sejarah}

Pada Pasal 3 Injil Barnabas memuat peristiwa kelahiran Yesus sebagai berikut.

There reigned at that time in Judaea Herod, by decree of Caesar Augustus, and Pilate was governor in the priesthood of Annas and Caiapha (Di sana yang memerintah atas tanah Yudea ialah Herodes dengan titah Kaisar Agustus, dan Pilatus adalah Gubernur, sedangkan Jabatan kepala Agama di pegang oleh Hannas dan Kayafas.

Injil Barnabas juga menyebutkan bahwa Yesus tidak benar-benar di salib, namun di angkat ke langit ketiga dan gantikan oleh Yudas Iskariot, hal ini tidak terdapat sama sekali dalam Injil-Injil Kanonik, Kisah itu misalkan terdapat di Pasal 215 berbunyi demikian:

When the soldiers with Judas drew near to the place where Jesus was, Jesus heard the approach of many people, wherefore in fear he withdrew into the house. And the eleven were sleeping.Then God, seeing $a$ the danger of his servant, commanded Gabriel, Michael, Rafael, and Uriel, his ministers, to take Jesus out of the world. The 
holy angels came and took Jesus out by the window that toward the South. They placed him in the third heaven in the company of angels blessing God for ever-more.

Yang diterjemahkan:

Ketika Tentara-tentara itu beserta Yudas mendekat ke tempat Yesus berada, Maka Yesus mendengar mendekatnya banya orang tersebut, oleh sebab itu dengan ketakutan ia menarik diri masuk ke dalam rumah, di mana ke sebelas muridnya sedang tertidur. Kemudian Allah melihat bahaya terhadap hamba-Nya itu, Ia telah memerintahkan Malaikat Gabriel, Mikhael, Rafael, dan Uriel, utusanutusannya, untuk membawa Yesus pergi dari dunia ini. Malaikatmalaikat suci itu telah datang dan membawa Yesus pergi melalui jendela yang menghadap kearah Selatan. Mereka menempatkan Dia ke langit ketiga dalam rombongan malaikat-malaikat yang memuja Allah selama-lamanya.

Penyebutan penggantian Yudas Iskariot yaitu peristiwa "Magic transformation" penyaliban itu di kisahkan pada pasal 216 yaitu:

Judas entered impetuously before all into the chamber whence Jesus had been taken up. And the disciples were sleeping. Whereupon the wonderful God acted wonderfully, insomuch that Judas was so changed in speech and in face to be like Jesus that we believed him to be Jesus. And he, having awakened us, was seeking where the Master was. Whereupon we marvelled,arid answered: Thou, Lord, art our master; hast thou now forgotten us?
(Yudas telah masuk dengan kekerasan mendahului semuanya ke dalam kamar, di mana Yesus telah diangkat. Waktu itu muridmuridnya tertidur. Allah membuat keajaiban akhirnya bahwa Yudas telah diubah bai bicaranya maupun wajahnya seperti Yesus, hingga kami percaya bahwa Dia sebagai Yesus)

\section{Tinjauan Kritis secara Biblika}

Harus disadari bahwa untuk belajar tentang seorang tokoh atau dokumen yang pernah ada secara historis, maka melihat sumber-sumber primernya (Primary resources) lebih baik daripada sumber sumber sekunder yang jauh dari akar sejarah dan sudah tidak ada lagi saksi mata yang masih hidup. Maka lakukan tinjauan historis kehidupan dan kematian Yesus, keagamaan dan geografis di jaman Yesus jelas kita harus merujuk kepada Alkitab sebagai sumber primer yang ditulis oleh Para Rasul Yesus yang hidup di abad pertama Masehi, di mana semua saksi mata baik yang pro dan kontra dengan kekristenan masih hidup.

\section{Terkait Keagamaan}

Ada dua hal yang terkait klaim dalam Injil barnabas bahwa Yesus adalah Kristus tetapi bukanlah Mesias, yang akan di kritisi. Jika memang benar bahwa Injil Barnabas telah ada sebelum Paus Gelasius I hidup, dan di tulis oleh Rasul Barnabas atau murid dari Rasul Barnabas, maka seharusnya klaim itu didukung oleh Para 
Rasul atau Bapa-bapa Rasuli bahwa Barnabas pernah menulis Injil. Tapi jelas hal itu tidak akan di temukan. Kedua, Barnabas orang Yahudi yang hidup di abad pertama, dimana Bahasa Internasional (Lingua Franca) pada saat itu adalah Bahasa Yunani, Bahasa yang dipergunakan untuk ibadah resmi di bait Allah adalah Bahasa Ibrani, Bahasa percakapan seharihari Yesus adalah Bahasa Aramaik, dan Bahasa pemerintahan adalah bahas latin. Namun, Penulis Injil Barnabas bahkan tidak tahu bahwa istilah Kristus yang di sebut dalam Pasal Judul dan pembukaan pasal 1 dan Mesias yang terdapat di Pasal 96 adalah sama. Bagaimana mungin, Barnabas orang yang lahir di abad pertama tidak mengetahui istilah umum yang dikenal pada jaman itu.

Hal itu dapat dilihat dalam Alkitab Perjanjian Baru, misalkan dalam Markus 1:1. Dalam Bahas Yunani di sana di tuliskan

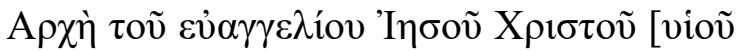
$\theta \varepsilon o \tilde{u}]$ (Mk. 1:1 GNT)

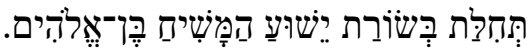

(Mk. 1:1 MHT)

Contoh lain dapat dilihat dalam Perjanjian lama misalkan dalam Imamat pasal 4:5

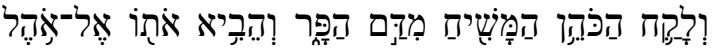
(Lev. 4:5 BHS)

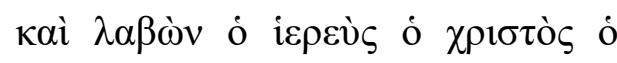

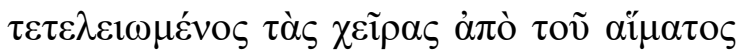

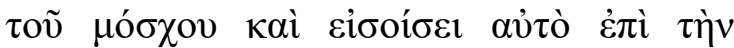

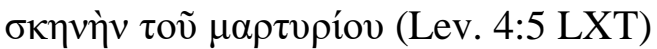

Kata khritou dalam bahasa aslinya (Yunani) Dalam terjemahan Bahasa Ibraninya menggunakan kata "Hamasiakh". Demikian juga sebaliknya, Alkitab Perjanjian lama dalam Bahasa Ibrani yang menggunakan kata "Hamasiakh" ketika diterjemahkan ke dalam Bahasa Yunani menjadi "Khristos". Karena memang faktanya bahwa Khristou dan Hamasiah atau Al-Masih adalah kata dengan arti yang sama yaitu yang diurapi. ${ }^{14}$ Untuk Perjanjian lama, kata Hamasiakh di gunakan untuk menunjuk utusan dengan tugas tertentu yang diurapi, yaitu menunjuk kepada Nabi, Imam dan Raja.

Kedua, Perlu ditegaskan bahwa Yesus adalah Mesias Ilahi yang dinubuatkan dalam Perjanjian Lama. Ayatayat yang dipercaya oleh orang Yahudi hanya untuk Mesias yang akan datang misalnya terdapat pada Ulangan 18:15; Mazmur 110:1, dan masih banyak lagi, namun berfokus kepada kedua ayat di atas akan jelas membuktikan Yesus memang adalah Mesias yang dinubuatkan dalam Perjanjian lama.

\footnotetext{
${ }^{14}$ Istilah itu sama dengan orang hidup di jaman ini tetapi tidak tahu kalua dog sama dengan anjing, atau orang jawa tidak tahu kalau ayam sama dengan Pithik.
} 
Ulangan 18:15 berbunyi:

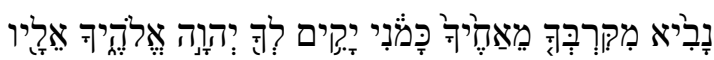

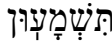

(Deut. 18:15 BHS)

Transliterasi:

Nabi' miqirbeka me'akheyka kamoni yaqim Leka Yhwh Eloheyka Elay Tishmaun.

Seorang Nabi dari tengah-tengahmu, dari antara saudara-saudaramu, sama seperti aku, akan dibagkitkan bagimu oleh Tuhan Allahmu, Dialah yang harus kamu dengarkan. Memang terdapat 3 arus penafsiran terhadap ayat ini. Beberapa kaum Islam yang mencari nubuatan ayat ini hanya berfokus kepada frasa "dari antara saudara-saudaramu" sehingga Jika Musa berasal dari orang Israel, maka Ismael adalah sudaranya, Maka nubuatan itu cocok dengan Nabi Muhammad. Karena kesamaan-kesamaan fisik antara Muhammad dan Musa. Kedua, adalah tafsiran orang-orang Yahudi modern untuk menghindari nubuatan untuk Yesus mereka mengubah kata "Nabi" dalam bentuk tunggal menjadi jamak. ${ }^{15}$ Dan yang ketiga arus Kekristenan yang menafsirkan Ayata ini hanya untuk Yesus Kristus.

${ }^{15}$ Rabbi Nossom Schurman, Humash Humashi Torah Im Targum Onkelos Farasi Haftarot wa Humash Megiot, Hebrew English (New York: Messorah Publication Ltd, 1994, hlm 199.
Ayat di atas tidak boleh dilepaskan dari konteksnya, bahwa konteks sedang membicarakan "Imam-imam orang Lewi, seluruh suku Lewi”. Kata mu di situ sekalipun memang adalah orang Israel secara umum, namun secara khusus sesuai konteksnya berbicara kepada Imam-imam orang Lewi seluruh suku Lewi. Jadi kata dari tengah-tengahmu dari antara saudarasaudaramu yaitu Israel terdiri dari 12 suku, maka Nabi yang sama seperti Musa akan muncul dari saudara suku lewi tapi masih dari tengah2 mereka yaitu Bangsa Israel.

Ketika menunjuk kepada Nabi' secara tata Bahasa ini jelas dalam Bahasa aslinya berbentuk Kata benda, maskulin Tunggal, absolut. Jadi jelas tidak bisa di artikan jamak seperti orang-orang Yahudi modern. Maka terjemahan LAI dengan menyebut "seorang Nabi" sudah tepat. Lalu, pertanyaanya siapakah seorang Nabi yang sama seperti Musa? Jawabannya adalah Yesus, bahkan Nabi Yang melebihi Musa. Musa berbicara tentang Allah Yesus pun berbicara mengenai Allah dalam kemanusiaan-Nya, sekalipun dalam keIlahian-Nya Ia menyeru Eigo Eimi, Aku adalah yang digunakan oleh Allah dalam Perjanjian Lama. Yesus pun menyeru dalam Bahasa Yunani Amen, Amen Lego Hemin seperti Nampak dalam teks berikut:

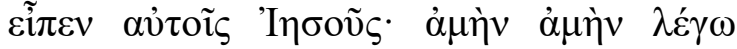

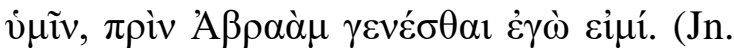


Jurnal Teologi \& Pelayanan ( Kerusso )

E-ISSN: 2714-9587

P-ISSN: 2407-554X

8:58 GNT) Sebab berbeda dari Nabi-nabi

Perjanjian lama yang hanya menyampaikan

firman yang berasal dari Allah dan menggunakan kata Amen di belakang (Bd. Mzm 41:13). Yesus justru mengucapkan berasal dari otoritasnya sendiri dan mengucapkan Amen di depan yang hanya diucapkan oleh Allah sendiri dalam Perjanjian Lama.

Kesamaan lain antara Yesus dan Musa adalah sama-sama Nabi Eksodus (Keluaran), selain itu Pelayanan keduanya di tandai dengan Mujizat. Yesus dan Musa sama-sama ketika usia 2 tahun mau dibunuh dan sama-sama dilarikan ke Mesir dan masih banyak kesamaan-kesamaan lain secara spesifik.

\section{Mzm 110:1}

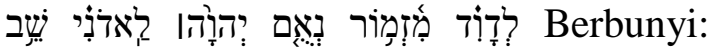

(Ps. 110:1 BHS)

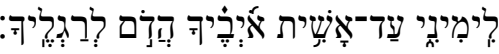

Nubuatan di atas sudah dipahami sebagai nubuatan akan datangnya Mesias. Rabbirabbi sebelum Yesus sudah memahami bahwa ayat tersebut berbicara mengenai Mesias. Contohnya adalah Rabbi Ahan Bar Haninan mengatakan bahwa Yahwe akan memanggil Mesias sebagai T(u)han/ Adonay dan menempatkannya di sebelah kanannya. ${ }^{16}$

${ }^{16}$ Risto Santala, The Messiah in the old Testament in The Light of Rabinical Writings (Jerusalem: aren Ahvah Meshishit, 1992) bandingkan dengan Leonardo Winarto Ketritunggalan dan Keesaan Allah Antara kesesatan dan kebenaran, Situbondo:
Jadi dengan Yesus mengutip ayat ini, Kotbah Petrus mengutip ayat ini dan dikenakan pada Yesus jelaslah Bahwa Yesus adalah Mesias Ilahi yang dinubuatkan Perjanjian lama. Apa makna Yesus duduk di sebelah kanan? Apakah seperti yang disalahpahami oleh orangorang yang menuduh Kristen menyembah tiga Allah (Triteisme)? Dengan mengatakan bahwa Yesus di sebelah kanan Allah berarti di sorga ada tiga takhta. Padahal Allah itu "beyond Time and space”, sehingga Ia tidak dapat dibatasi oleh ruang dan waktu. ${ }^{17}$ Maka di hadapannya tentu tidak ada kanan, kiri, muka, belakang, atas dan bawah. Maka ayat itu berkaitan dengan Latar Belakang geografis di Israel, dimana Bait Suci menghadap ke sebelah timur, di sebelah selatan Ruang Maha Kudus yang merupakan representasi kehadiran Allah dalam Perjanjian Lama adalah Takhta (Singgahsana) raja Israel yang memerintah. Jadi Tuhan berfirman kepada Mesias Ilahi yang akan datang untuk duduk di sebelah selatan memegang kekuasaan sebagai Mesias, di mana Raja-raja Perjanjian Lama selalu gagal sebagai Mesias.

\footnotetext{
Memra Publishing, 2019, hal 29-30.

${ }^{17}$ Frederich Oscar L. Lontoh, UNDERSTANDING THE DOCTRINE OF THE TRINITY, Jurnal Kerugma vol 2, no 1, April 2019, no 1
} 
Dari Kedua ayat itu cukup membuktikan bahwa Yesus adalah Kristus yang sama artinya dengan Mesias. Selanjutnya tekait dengan gaya sumpah Yesus, Demi Allah yang aku berdiri di hadapan-Nya jelas-jelas tidak pernah terlihat dari Potret Yesus dalam Injil-injil Kanonik. Malahan hal itu Nampak lebih dekat dengan Hadist-hadist Muslim. ${ }^{18}$ Yesus dalam Injil-injil Kanonik tidak pernah meminjam otoritas Allah atau orang lain Ia selalu berkata dari diri-Nya sendiri, karena memang Yesus adalah Allahmanusia sejati.

Terkait dengan kesalahan pencatatan tentang Tahun Yobel dalam Injil Barnabas, siapapun yang akrab dengan tradisi Yahudi yang bersumber dari Taurat, maka akan dapat membandingkan langsung mengenai jumlah tahun Yobel. Menurut Kitab Taurat dalam Imamat 25:122; 27:16-24 Tahun Yobel dirayakan setiap 50 tahun sekali. Berbeda dengan Injil barnabas yang menyebut angka 100 tahun untuk memperingati Yobel. Pasalnya dalam sejarah Gereja tercatat Paus Bonaficius VIII pernah mengeluarkan perayaan tahun Yobel setiap 100 tahun sekali. ${ }^{19}$ Dan setelahnya, Paus Clemen VI

\footnotetext{
${ }^{18}$ Bambang Noorsena, Ibid, hal 31

${ }^{19}$ Bandingkan H. Thurston (1910). 'Holy Year of Jubilee', in The Catholic Encyclopedia VIII (New York:

Robert Appleton Company, New York), 1997
}

mengubahnya menjadi 50 tahun kembali. ${ }^{20}$ Dimana hal ini sekaligus membuktikan kemungkinan paling awal Injil Barnabas di tulis yaitu tidak mungkin sebelum tahun 1300, karena Paus Bonaficius VIII menjabat tahun $1300 \mathrm{M}$. setelah itu tercatat pernah berulangkali perubahan perayaan Yobel oleh Paus-Paus setelah Bonaficius.

\section{Terkait Letak Geografis}

Injil Barnabas tidak mungkin di tulis oleh Barnabas murid Yesus abad $1 \mathrm{M}$, karena selain teks aslinya berbahasa Italia, tetapi penulis juga tidak memahami daerah Israel-Palestina. Yesus dikatakan oleh Injil Barnabas berlayar ke Nazaret, Padahal Peta geografis Palestina-Israel, Nazaret adalah sebuah kota yang terletak di dataran tinggi, terletak di ketinggian $350 \mathrm{~m}$, dan jarak ke Laut Galilea adalah $23 \mathrm{Km} \cdot{ }^{21}$ Oleh sebab itu mustahil Yesus singgah di Nazaret menaiki perahu.

Kapernaum justru adalah Kota Pesisir yang terletak di Pantai Laut Galilea. Tinggi permukaannya lebih tinggi daripada Nazaret, bagaimana mungkin Injil Barnabas yang meminjam nama Rasul Barnabas tidak tahu geografis yang

\footnotetext{
${ }^{20}$ Weber, Nicholas Aloysius (1908). "Pope Clement VI" . In Herbermann, Charles (ed.). Catholic Encyclopedia. 4. New York: Robert Appleton Company

${ }^{21}$ http://www.sttyuppentek.ac.id/id4/2-29052802/Nazaret_34442_ista_sttyuppentek.html
} 
Jurnal Teologi \& Pelayanan ( Kerusso )

E-ISSN: 2714-9587

P-ISSN: 2407-554X

demikian. ${ }^{22}$ Catatan Injil Barnabas justru Yesus Went Up to Capernaum, padahal seharusnya Went Down. Hal ini mungkin saja kutipan yang tanpa teliti mengambil dari cerita-cerita dalam Injil Kanonik. ${ }^{23}$

\section{Terkait Sejarah}

Injil Barnabas banyak melakukan Anakronisme $^{24}$ di dalam Kepengarangan injilnya. Dalam Pasal 3 di sebutkan tahun kelahiran Yesus ketika beberapa penguasa memerintah dan menjadi Imam besar. Padahal menurut catatan sejarah (yang sesuai dengan Perjanjian Baru), Pilatus menjabat sebagai gubernur atau wali negeri di wilayah itu tahun 29 Masehi. $^{25}$ Yesus lahir kira-kira 4-5 tahun sebelum kalender Masehi yang sekarang. Jadi, jelas ada anakronisme yang dilakukan oleh penulis Injil Barnabas, karena memang jauh dari abad 1 Masehi dan tidak menjadi saksi mata kejadian.

Kedua, Injil Barnabas lebih paralel dengan cerita Alquran dari pada cerita Injil-Injil Kanonik mengenai Penyaliban Yesus. $^{26}$ Yesus dikatakan diangkat ke

\footnotetext{
${ }^{22}$ Itu sama halnya dengan orang Surabaya yang mengatakan, "Mari kita turun ke Kota Batu". Padahal jelas-jelas Kota Batu terletak di Dataran tinggi.

${ }^{23}$ Bandingkan dengan Matius 8:1; 8:5; 8:28 dll.

${ }^{24}$ Anakronisme adalah salah jaman (kesalahan secara kronologi sejarah)

${ }^{25}$ See 'Pontius Pilate', in Encyclopadia Britannica Online

$<$ http://www.britannica.com/biography/Pontius-

Pilate $>$.

${ }^{26}$ Amina Inloes, Ibid
}

langit ketiga dan di gantikan oleh Yudas dalam keajaiban pergantian ucapan dan wajah. Melakukan tinjauan Historis layak dilakukan baik secara biblical maupun dari literature non biblical. Dari ayat-ayat Alkitab ke-empat Injil memberi kesaksian yang satu bahwa Yesus sungguh-sungguh disalib dan sungguh-sungguh mati. 2 kesaksian (Matius dan Yohanes) berasal dari 12 Rasul Yesus, dan 2 kesaksian (Markus dan Lukas) berasal dari kelompok 70 Rasul menurut keterangan Hipolitus. Selain itu Petrus, Paulus dan Para Rasul penulis Perjanjian Baru juga memberi kesaksian yang sama bahwa Yesus benarbenar mati, kemudian dibangkitkan pada hari ketiga sesuai nubuatan Perjanjian lama.

Catatan Josephus dalam Antiquities 18.3.3 dan juga dalam Testimonium Flavianum juga menulis tentang penyaliban Yesus: ${ }^{27}$

"Ginetai de Kata touton ton xromon Iesous Sophos aner, eige andra auton legein chre............" Artinya:

"Pada kira-kira waktu ini, hiduplah Yesus, seorang yang bijaksana, jika memang seseorang seharusnya menyebut dia seorang manusia. Karena ia adalah seseorang yang mengadakan hal-hal yang mengejutkan dan adalah seorang

\footnotetext{
${ }^{27}$ Robert E Van Vorst, Jewish Outside the New Testament (Michigan: W. B. Eerdmans 2000, 85)
} 
guru bagi orang-orang yang menerima kebenaran dengan senang hati. Ia memenangkan banyak orang Yahudi dan banyak orang Yunani. Ia adalah Sang Kristus. Ketika Pilatus, karena mendengar bahwa ia dikenai tuduhan oleh orang-orang dengan jabatan tertinggi di antara kami, telah menjatuhkan hukuman salib kepadanya, mereka yang dari mulanya sudah mengasihi dia tidak melepaskan kasih sayang mereka kepadanya. Pada hari ketiga ia menampakkan diri kepada mereka dalam keadaan kembali hidup, karena nabi-nabi Tuhan telah menubuatkan hal-hal ini dan tak terhitung banyaknya hal-hal menakjubkan lainnya mengenai dia. Dan suku Kristen, demikian mereka disebutkan menurut namanya, sampai saat ini masih ada."

Tulisan Tacitus, dan sejarahwansejarahwan sekuler lain juga menuliskan hal yang sama padahal mereka bukan dari pendunkung atau pengikut Kristus.

Tacitus misalkan menulis dalam Annals, menyinggung soal penyaliban Yesus:

Oleh karena itu untuk memadamkan desas-desus itu, Nero menggantikan korban dan menghukum dengan cara paling licik dan kejam kelompok orang............. Kristus yang namaNya diberikan pada mereka telah dihukum mati atas vonis dari procurator Pontius Pilatus Pada

zaman $\begin{aligned} & \text { Tiberius } \\ & \text { kaisar............ }\end{aligned}{ }^{28}$

\section{Tulisan Rabbi-Rabbi Yahudi}

Orang yahudi tidak hanya memiliki Tanakh sebagai tulisan keagamaan tetapi juga tulisan lain untuk mengatur kehidupan kerohanian dan keagamaan, yang merupakan tradisi lisan. Kutipan Talmud yang menyinggung tentang penyaliban Yesus yaitu:

"Jesus was Crucified one day before Passover. We warned him for 40 days that he would be killed because he was a magician and planned to deceive Israel with his delusions" $" 29$

Yang berarti:

"Yesus telah disalibkan sehari sebelum Paskah. Sebeumnya, kami memperingatkan Dia selama 40 hari bahwa Ia akan dibunuh karena Dia adalah seorang penyihir, dan menyesatkan Israel dengan imajinasi-imajinasiNya."

\section{KESIMPULAN (CONCLUSION)}

Sejak munculnya hingga saat ini memang Injil barnabas mengundang ketertarikan dari banyak pihak, ada yang mengabaikan begitu saja, ada yang antusias mennaggapi, bahkan menjadikan buku ini untuk melakukan syiar agama mereka. Namun yang perlu di catat setelah melihat

\footnotetext{
${ }^{28}$ F.F Bruce, Dokumen-dokumen Perjanjian Baru. Alihbahasa: R. Sooedarmo (Jakarta: BPK Gunung Mulia, 1997) hal 100

${ }^{29}$ Faris al-Qayrawani, was Christ realy Crucified? (Austria: Light of Life, 1994, hal 47).
} 
buku Injil barnabas baik menurut buktibukti dari para peneliti naskah maupun dari perbandingannya dengan Alkitab sebagai sumber primer catatan hidup Yesus, jelaslah bahwa buku ini tidak mungkin di tulis oleh Rasul Barnabas yang hidup di abad 1, karena kesalahan-kesalahan keagamaan, kesalahan geografis, anakronisme sejarah dan berbagai macam kesalahan lainnya. Oleh sebab itu layaklah Injil palsu ini di pelajari untuk melihat jenis-jenis dan cara-cara ajaran menyimpang, dan untuk memberikan kesadaran bagi pembacanya agar dapat membedakan mana yang merupakan wahyu yang historis dengan mitos yang ahistoris. Dengan melihat dari catatan dalam Injil Barnabas sudah dapat ditentukan bahwa buku ini tidak mungkin ditulis sebelum tahun 1300 bahkan banyak ahli yang setuju buku ini ditulis dalam Bahasa Italia, oleh Penulis bernama Fra Marino atau Mustafa de Aranda dengan motif teologis yang barangkali punya masalah pribadi dengan gereja Katolik saat itu. Mempelajari Injil Barnabas, justru membuktikan bahwa Alkitab yang di pegang orang Kristen adalah Injil yang asli yang memang ditulis oleh Para saksi mata yang hidup di abad pertama yang punya kesinambungan dengan Perjanjian lama, yaitu Kitab Taurat, Mazmur dan Kitab para Nabi.

\section{DAFTAR PUSTAKA (REFERENCES)}

[1] A M I N A I N L O E S, The Gospel of Barnabas: A Muslim

Forgery?, Source of Islamic Knowledge

[2] Bruce F.F, Dokumen-dokumen Perjanjian Baru. Alihbahasa: R. Sooedarmo (Jakarta: BPK Gunung Mulia), 1997

[3 ]Cotterell F. P., 'The Gospel of Barnabas', in Vox Evangelica X (1977),

[4] Elliott J. k., The Apocryphal New Testament, Oxford: Oxford University Press, 2005.

[5] Fletcher J. E,The Spanish Gospel of Barnabas', in Novum Testamentum XVIII, Fasc. 4 (1976),

[6] End, van Den, Sejarah Perjumpaan Gereja dengan Islam, Jakarta: Sekolah Tinggi Teologia, 1978

[7] Hennecke, E dan W. Schneemelcher, New Testament Apocrypha, London, 1973 [8] Joosten, Jan. "The Gospel of Barnabas and the Diatessaron". Harvard Theological Review, 2002

[9] Lonsdale dan Laura Ragg, The Gospel Of Barnabas, Edited and translated form Italian Ms, Oxford: Clarendon Press. [10] Lontoh, Frederich Oscar L., understanding the doctrine of the trinity, Jurnal Kerugma vol 2, no 1, April 2019, no [11] Noorsena, Bambang, Telaah Kritis 
Jurnal Teologi \& Pelayanan ( Kerusso )

E-ISSN: 2714-9587

P-ISSN: 2407-554X

terhadap Injil Barnabas (Asal-Usul,

Historisitas dan Isinya), Yogyakarta: Andi

Offset, 1990 hal 3

[12] Ryad, Umar, IN PURSUIT OF A

'TRUE' GOSPEL: RIdTA'S ARABIC

EDITION OF THE GOSPEL OF

BARNABAS, JSTOR: BRILL

[13] Santala Risto, The Messiah in the old Testament in The Light of Rabinical Writings (Jerusalem: aren Ahvah Meshishit, 1992) .

[14 ] Schurman Rabbi Nossom, Humash Humashi Torah Im Targum Onkelos Farasi Haftarot wa Humash Megiot, Hebrew English (New York: Messorah Publication Ltd, 1994

[15] Schwartz E., Zeitschrift fur Neuestestamentliche Wissensehaft, 1930

[16] Slomp, Jan. Pseudo Barnabas in the context of Muslim-Christian Apologetics, dalam Al-Mushir XVl (1474). hlm.

[17] Thurston H.. 'Holy Year of Jubilee', in The Catholic Encyclopedia VIII (New York: Robert Appleton Company, New York), 1997

[18] Vorst, Robert E Van, Jewish Outside the New Testament, Michigan: W. B: Eerdmans 2000,

[19] Weber, Nicholas Aloysius, Pope Clement VI. In Herbermann, Charles (ed.). Catholic Encyclopedia. 4. New York: Robert Appleton Company,
[20] Winarto, Leonardo Ketritunggalan dan Keesaan Allah Antara kesesatan dan kebenaran, Situbondo: Memra Publishing, 2019

[21] http://www.sttyuppentek.ac.id/id4/22905-

2802/Nazaret_34442_ista_sttyuppentek.ht ml diakses 29 Maret 2021 